\title{
The Effect of Sample Size on the Heat Release Rate of Charring Materials
}

\author{
STEVEN J. RITCHIE, KENNETH D. STECKLER, \\ ANTHONY HAMINS, THOMAS G. CLEARY, \\ JIANN C. YANG and TAKASHI KASHIWAGI \\ Building and Fire Research Laboratory \\ National Institute of Standards and Technology \\ Gaithersburg, MD 20899 USA
}

\begin{abstract}
The burning of a horizontal wood slab situated atop an insulating substrate was modeled using three coupled submodels for the gas-phase, wood, and substrate processes. A global analytical model was used to determine the radiative and convective heat feedback from the gas-phase combustion to the wood surface. The char-forming wood model was a one-dimensional numerical computation of the density change as a function of position and time. The backside boundary condition of the wood was treated as conductive heat loss into a substrate material modeled by the heat conduction equation. The condensed-phase model results were tested by exposing Douglas Fir samples to an external flux in a nitrogen environment (no combustion). Heat release rate calculations are compared to experimental results for Douglas Fir samples of $0.1 \mathrm{~m}$ and $0.6 \mathrm{~m}$ diameter. Both theory and experiments show that, for the conditions studied, the heat release rate is nearly independent of the specimen diameter except for the initial peak and the affect of this peak on the first portion of the quasi-steady settling period. Model predictions also indicate that the second peak, which follows the settling period, is very sensitive to the thickness of the insulating substrate.
\end{abstract}

KEYWORDS: burning rate, char, diameter, Douglas Fir, gasification rate, heat feedback, wood

\section{INTRODUCTION}

It has been shown that the fire size has an impact on the mass burning flux of noncharring liquid and solid fuels through the influence of heat feedback from gas-phase combustion [1]. However, the effect of size on the mass loss rate under fire conditions of charring solids has not been studied in detail. There has been a problem in extrapolating bench scale data such as the cone calorimeter results to full scale geometries such as burning furniture and compartments. This has led to the development of intermediate scale apparatuses which can provide more appropriate heat release rate data by using a more realistic burning scenario (i.e. vertical walls) [2]. The approach taken in this paper is to try to understand the effects of scale on burning behavior by 
examining the problem fundamentally using experimental and numerical analyses to look at how changes in the size of a sample influence the heat release rate of wood under fire-like conditions.

In pool fires, the burning process is a complex coupling between fuel gasification and heat feedback to the fuel surface from the flame zone. For this study, a circular sample of Douglas Fir was subjected to an external flux and ignited using a pilot. The heat feedback to the surface from the gas-phase flame zone and the gas-phase combustion were modeled globally. This submodel was coupled to a one-dimensional numerical condensed-phase thermal degradation model. The solid-phase model solved the heat conduction equation for a fixed-thickness sample with locally varying density, thermal properties and reaction rates to compensate for char formation. Any radial variation of local heat flux over the sample surface was neglected [3].

Several experiments were run to validate the theoretical analysis. In one set of measurements, the wood sample was subjected to fire-like heat fluxes in nitrogen using a thermal gasification apparatus. These results provide a check of the solid-phase model without any gas-phase heat feedback. The heat release rate of burning Douglas Fir samples with $0.1 \mathrm{~m}$ and $0.6 \mathrm{~m}$ diameters were measured using the cone calorimeter and large-scale radiant panel facility for comparison with the complete model predictions.

\section{MODEL DESCRIPTION}

\section{Condensed-Phase Submodels}

The condensed-phase model follows the work of Parker [4] and Atreya [5]. Modifications were made to include the influence of a backing substrate and to remove moisture effects. The physical configuration is a sample of thickness, L, placed on a substrate of thickness, S. Initially, the sample and substrate temperatures are equal to the ambient. At time $=0$, the exposed sample surface is subjected to a constant external heat flux. As the sample temperature increases, the material begins to degrade and mass is lost to the gas phase. Since this is a char-forming material, the sample thickness is kept constant. The model is based on the determination of the density change through an Arrhenius-controlled rate equation. All gasified products are instantaneously transported to the sample exterior. Steckler et al. [6] have shown that the backside boundary condition strongly affects the gasification rate due to its influence on the heat transfer characteristics. To properly compare with experimental measurements, conductive losses to the substrate are included. The physical constants and nomenclature are shown in Table 1.

Within the char-forming sample, the governing equations for energy and density are given by:

$$
\begin{aligned}
& \overline{\rho c} \frac{\partial T}{\partial t}=\frac{\partial}{\partial x}\left[\lambda_{w} \frac{\partial T}{\partial x}\right]+\frac{\partial \rho_{w}}{\partial t}\left(\Delta H_{v}-C\left(T-T_{o}\right)\right) \\
& \frac{\partial \rho_{w}}{\partial t}=-\rho_{w o}\left[\frac{\rho_{w}-\rho_{w f}}{\rho_{w o}}\right]^{N} A e^{-E_{a} / R_{u} T}
\end{aligned}
$$

where:

$$
C=\frac{\rho_{w o} \overline{c_{p, w o}}-\rho_{w f} \overline{c_{p, w f}}}{\rho_{w o}-\rho_{w f}}-\overline{c_{p, g}}
$$




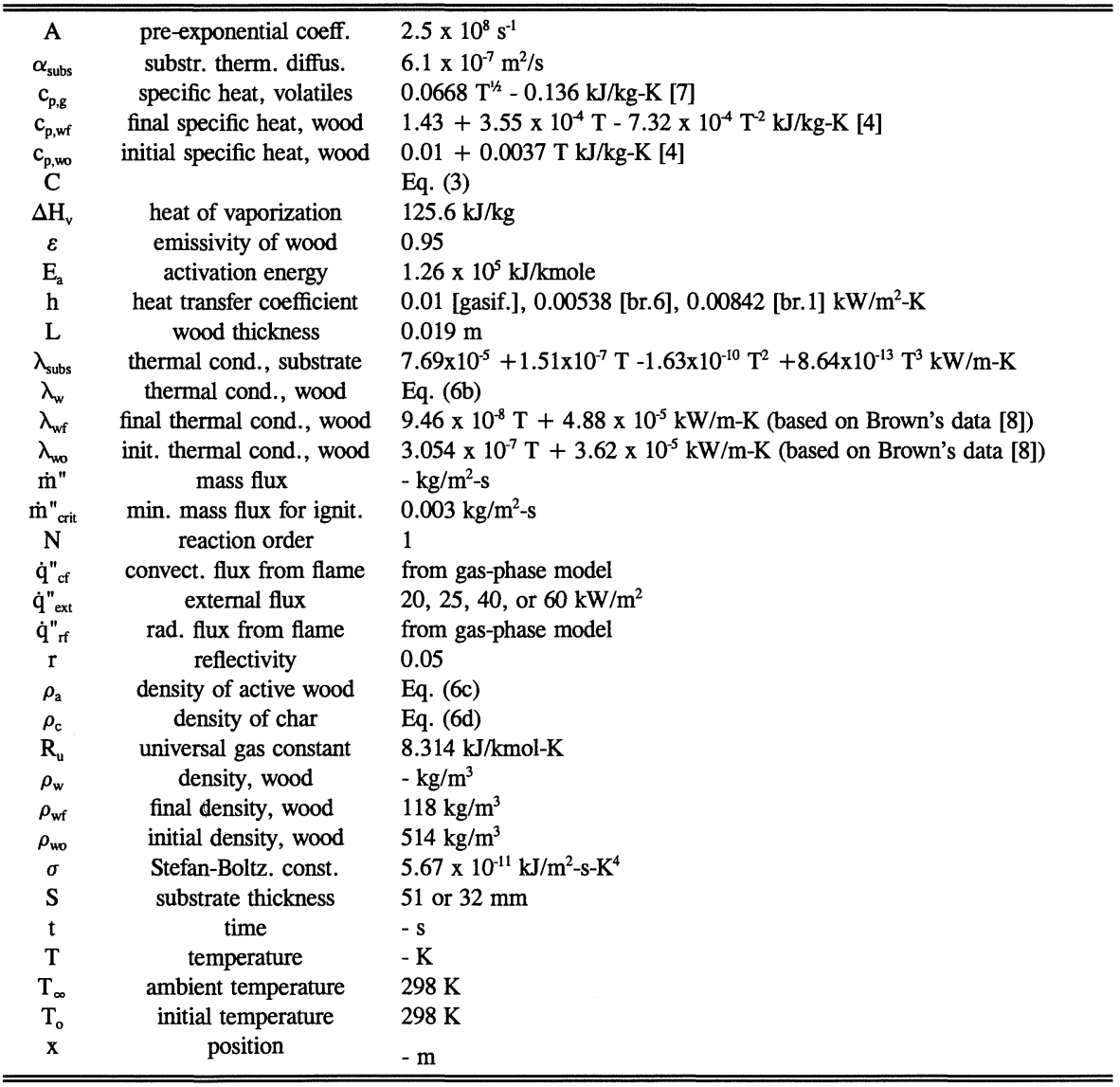

The bars in Eq. (3) denote evaluation at the average of the initial temperature, $T_{0}$, and current local temperature, $T$. An energy balance at the surface includes the incident energy input, losses to the surroundings and conduction into the sample:

$$
\dot{q}_{\text {inc }}^{\prime \prime}=\left[\lambda_{w} \frac{\partial T}{\partial x}\right]_{L, t}+\epsilon \sigma\left[T_{L, t}^{4}-T_{\infty}^{4}\right]+h\left[T_{L, t}-T_{\infty}\right]
$$

where the incident flux, $\dot{\mathrm{q}}_{\text {inc }}$ is enhanced by the flame heat feedback once the mass loss can sustain a flame:

$$
\dot{q}_{\text {inc }}^{\prime \prime}=\left\{\begin{array}{c}
(1-r) \dot{q}_{\text {ext }}^{\prime \prime} ; \dot{m}^{\prime \prime}<\dot{m}_{c r i t}^{\prime \prime} \\
(1-r)\left(\dot{q}_{\text {ext }}^{\prime \prime}+\dot{q}_{r f}^{\prime \prime}\right)+\dot{q}_{c f}^{\prime \prime} ; \dot{m}^{\prime \prime} \geq \dot{m}_{c r i t}^{\prime \prime}
\end{array}\right.
$$

There is a convective loss term in Eq. (4) that applies only when no flame is present. When there is a flame, the convective heat transfer is defined by the term in Eq. (5). 
The following definitions are used to compensate for the changing thermal properties as the virgin material chars. Heat capacity and thermal conductivity are functions of density and temperature:

$$
\begin{array}{lll}
\overline{\rho c}=\rho_{a} c_{p, w o}+\rho_{c} c_{p, w f} & (a) & \lambda_{w}=\lambda_{w o}\left(\frac{\rho_{a}}{\rho_{w o}}\right)+\lambda_{w f}\left(\frac{\rho_{c}}{\rho_{w f}}\right) \\
\rho_{a}=\rho_{w o} \frac{\left(\rho_{w}-\rho_{w f}\right)}{\left(\rho_{w o}-\rho_{w f}\right)} & (c) & \rho_{c}=\rho_{w}-\rho_{a}
\end{array}
$$

where $c_{p, w o}, c_{p, w f}, \lambda_{w o}$, and $\lambda_{w f}$ are functions of local temperature, $T$.

The mass flux is determined by integrating the rate of density change over the sample thickness.

At the sample/substrate interface, a conductive energy balance and temperature continuity condition must be met. The heat equation describes the conductive transfer through the substrate. Either an adiabatic or blackbody-radiation back boundary condition is applied to the substrate to complete the formulation. Derivatives are approximated using central differencing. A CrankNicholson routine is used to solve the equation sets for the substrate and sample separately. Coupling at the interface is achieved by iterating until both boundary conditions are met.

\section{Gas-Phase Submodel}

Once the mass loss from the surface reaches a critical value which can sustain a flame, the incident heat flux defined in Eq. (5) includes the radiative and convective heat feedback from the flame zone. In the model, the influence of sample diameter is determined by these two feedback terms, which are controlled by the mass-loss rate from the sample and several fuel properties. The gas-phase model and material-property determination for Douglas Fir are explained below.

The radiation heat feedback term in Eq. (5) is modeled as isothermal emission from gaseous $\mathrm{CO}_{2}$ and $\mathrm{H}_{2} \mathrm{O}$ and gray-body emission from soot. A correction for spectral overlap by these emitters is included. Total radiation to the surface, $\dot{\mathrm{q}}_{\mathrm{rf}}$, from the flame at temperature $\mathrm{T}_{\mathrm{f}}$ is given by [9]:

$$
\dot{q}_{r f}^{\prime \prime}=\sigma T_{f}^{4}\left[1-\left(1-\varepsilon_{\text {soot }}\right)\left(1-\varepsilon_{\mathrm{H}_{2} \mathrm{O}}\right)\left(1-\varepsilon_{\mathrm{CO}_{2}}\right)\right]
$$

Gas emissivities for carbon dioxide, $\varepsilon_{\mathrm{CO} 2}$, and water, $\varepsilon_{\mathrm{H} 20}$, are calculated using Leckner's algorithm [10]. The soot emissivity, $\varepsilon_{\text {soot }}$, is approximated as a gray body emitter [11] represented by a characteristic mean-beam path length, $L_{m}$, the soot volume fraction, $f_{v}$, and the optical constants for soot particles. For this geometry, the mean beam length, $\mathrm{L}_{\mathrm{m}}$, is approximated [12] as:

$$
L_{m}=3.6 V A_{f}^{-1}
$$

The volume, $\mathrm{V}$, and surface area, $\mathrm{A}_{\mathrm{f}}$, are approximated by assuming the flame is a right circular cylinder defined by the sample radius and a height determined using Heskestad's correlation [13]. The infrared-averaged optical constants for soot particles are given by $n=3.49$ and $\mathrm{k}=2.17$ [14]. The soot volume fraction, $\mathrm{f}_{\mathrm{v}}$, is determined by correlating the data of Bard and Pagni [15] to smoke point height for various fuels [16]. The existing data [17] suggests that for pool diameters less than $2 \mathrm{~m}, \chi_{\mathrm{A}}$ and $\chi_{\mathrm{R}}$ are not a function of scale. Since $\mathrm{f}_{\mathrm{v}}$ and $\chi_{\mathrm{A}}$ are related, the model assumes $f_{v}$ is independent of sample size. 
The flame is modeled as a homogeneous mixture of entrained air, combustion products $\left(\mathrm{CO}_{2}\right.$, $\mathrm{H}_{2} \mathrm{O}$, and soot), and unburnt fuel. The global temperature, $\mathrm{T}_{\mathrm{f}}$, is calculated using an enthalpy balance about a control volume encompassing the gas-phase cylindrical flame:

$$
\left(\chi_{A}-\chi_{R}-\chi_{F}\right) H_{c}+\overline{c_{p, f}}\left(T_{s}-T_{o}\right)=\int_{T_{o}}^{T_{f}} \sum_{i} x_{p, i} c_{p, i}\left(T^{*}\right) d T^{*}
$$

where $c_{p, i}(T)$ is the vapor specific heat of the $i^{\text {th }}$ gas species [18] and $\overline{c_{p, f}}$ is the vapor specific heat of fuel leaving the surface evaluated at the average of $T_{0}$ and fuel-surface temperature, $T_{s}$. The species concentrations in the flame are determined from stoichiometric combustion of $\mathrm{C}_{3.4} \mathrm{H}_{6.2} \mathrm{O}_{2.5}$, the amount of entrained air, and the concentration of unburnt fuel (from $\chi_{\mathrm{A}}$ ). The moles of air entrained into the fire are determined using a modified form of Delichatsios' correlation [19]. Intermediate gas species $\left(\mathrm{CO}, \mathrm{H}_{2}\right.$, etc.) and soot are neglected, except in a global sense through $\chi_{\mathrm{A}}$. Because the specific heats are temperature dependent and the value of $\chi_{\mathrm{F}}$ (the fraction of energy lost to the surface) is defined by the heat feedback, an iterative approach is used for the calculation.

The convective feedback term, $\dot{\mathrm{q}}{ }_{\mathrm{cf}}$ in Eq. (5), is approximated using the stagnant film model [12]. A natural convection heat transfer coefficient for a hot surface facing upwards [20] is used.

For simplicity, the model treats wood as a single component fuel, with the gas-phase properties invariant in time following ignition. The samples used in the experiment were conditioned and the mass percentage of water was measured at $7 \%$ using a solid-state moisture detector. The remaining composition was taken from Parker [4]. The calculated heat of combustion for the volatiles in Douglas Fir is $12.6 \mathrm{~kJ} / \mathrm{g}$. The measured heat of combustion using the cone calorimeter was $12.0 \mathrm{~kJ} / \mathrm{g}$ yielding an estimated combustion efficiency, $\chi_{\mathrm{A}}$, of 0.95 . A radiative heat loss fraction, $\chi_{R}$, was determined using an estimated smoke point height of $0.16 \mathrm{~m}$ and the smoke point height relationship of Tewarson [16]. Table 2 lists the data used in the computations. Further details of the gas-phase model can be found in the report by Hamins, et al [21].

TABLE 2. Nomenclature and parameter values for gas-phase model

\begin{tabular}{ccl}
\hline \hline $\mathrm{A}_{\mathrm{f}}$ & area of flame surface & see text in section Gas-Phase Submodel \\
$\mathrm{A} / \mathrm{F}$ & stoichiometric air/fuel ratio & 4.05 \\
$\mathrm{c}_{\mathrm{p}, \mathrm{f}}$ & vapor sp. ht. of fuel leaving surface & assumed equal to values for heptane $\left(\mathrm{C}_{7} \mathrm{H}_{16}\right)[18]$ \\
$\mathrm{c}_{\mathrm{p}, \mathrm{i}}$ & vapor sp. ht. of $\mathrm{i}^{\text {th }}$ gas species & values for $\mathrm{H}_{2} \mathrm{O}, \mathrm{CO}_{2}, \mathrm{~N}_{2}, \mathrm{O}_{2}, \mathrm{C}_{7} \mathrm{H}_{16}[18]$ \\
$\varepsilon_{\mathrm{i}}$ & emissivity of $\mathrm{i}^{\text {th }}$ gas species & Lechner's algorithm [10] \\
$\varepsilon_{\mathrm{soot}}$ & emissivity of soot & see text in section Gas-Phase Submodel \\
$\mathrm{f}_{\mathrm{v}}$ & soot volume fraction & $2 \times 10^{-7}$ \\
$\mathrm{H}_{\mathrm{c}}$ & heat of combustion & $12.6 \times 10^{3} \mathrm{~kJ} / \mathrm{kg}$ \\
$\mathrm{L}_{\mathrm{m}}$ & mean beam length, flame & Eq. (8) \\
$\mathrm{T}_{\mathrm{f}}$ & flame temperature & Eq. $(9)$ \\
$\mathrm{V}$ & flame volume & see text in section $\mathbf{G a s}-\mathbf{P h a s e}$ Submodel \\
$\mathrm{x}_{\mathrm{p}, \mathrm{i}}$ & mole fraction of $\mathrm{i}^{\text {th }}$ product & determined from stoich. reaction of $\mathrm{C}_{3.4} \mathrm{H}_{6.2} \mathrm{O}_{2.5}$ \\
$\chi_{\mathrm{A}}$ & combustion efficiency & 0.95 \\
$\chi_{\mathrm{F}}$ & fraction of energy lost to surface & determined from $\dot{\mathrm{q}}^{\prime \prime}{ }_{\mathrm{rf}}$ and $\dot{\mathrm{q}}_{\mathrm{cf}}{ }_{\mathrm{cf}}$ (gas-phase model) \\
$\chi_{\mathrm{R}}$ & radiative heat-loss fraction & 0.3 \\
\hline \hline
\end{tabular}




\section{EXPERIMENTAL APPROACH}

Three experimental apparatuses were used to validate the model results. In each apparatus the specimen was tested over a substrate of Pittsburgh Corning Foamsil-28* rigid foamed glass insulation. The cone calorimeter [22] is a standard test. Its specimens were tested on $51 \mathrm{~mm}-$ thick substrate insulation. The large radiant panel facility and thermal gasification apparatus are similar to the cone and are described briefly below.

\section{Radiative Gasification Apparatus}

The gasification apparatus is shown schematically in Fig. 1. The cylindrical chamber is $0.61 \mathrm{~m}$ in diameter and $1.70 \mathrm{~m}$ in height. Two windows provide optical access. The chamber walls are water cooled to $25^{\circ} \mathrm{C}$. Product and ambient gases are removed via an exhaust duct by a constant nitrogen flow of $7.67 \mathrm{l} / \mathrm{s}$ at $25^{\circ} \mathrm{C}$. The cone-heater temperature was fixed at $750{ }^{\circ} \mathrm{C}$ to maintain a constant emission spectrum for all tests. Incident heat flux to the sample was varied by changing the distance between the sample and heater. A water-cooled shutter was extended to protect the sample from the incident heat flux prior to testing. Flux levels varied about $8-10 \%$ across a $0.1 \mathrm{~m}$ diameter. The sample, with no aluminum foil attached to its back or edge, was placed in a $0.1 \mathrm{~m}$ diameter $\times 19 \mathrm{~mm}$ deep cavity cut into a $51 \mathrm{~mm}$ thick $\mathrm{x} .127 \mathrm{~m}$ diameter brick of the substrate insulation as shown in Fig. 1. Load cell data were taken every $0.5 \mathrm{~s}$. Static load cell calibration indicated an error $<1 \%$ over a $100 \mathrm{~g}$ range.

\section{Large Radiant Panel Facility}

The large radiant panel facility is shown schematically in Fig. 2. This facility consists of two rectangular radiant panels angled $20^{\circ}$ from the horizontal, facing the sample. Aluminum foil was stapled to the $0.6 \mathrm{~m}$ specimen's edge and back prior to placing it on a horizontal slab of $51 \mathrm{~mm}$ thick substrate insulation. The sample/substrate was positioned at a location where the flux was $25 \mathrm{~kW} / \mathrm{m}^{2}$ ( $\sim 7 \%$ variation across a $0.6 \mathrm{~m}$ diameter). An insulated panel covered the surface before the test. Piloted ignition was achieved using a $\sim 100 \mathrm{~W}$ propane pilot flame positioned 60 $\mathrm{mm}$ above the surface. Heat release rate was determined using oxygen-consumption calorimetry.

\section{Test Sample Preparation}

The Douglas Fir samples were composed of tongue and groove flooring material that was $\sim 19$ $\mathrm{mm}$ thick $\mathrm{x} .127 \mathrm{~m}$ wide. For the gasification tests, $0.1 \mathrm{~m}$ diameter samples were cut from the flooring. The wood grain spacing ranged from $\sim 0.4 \mathrm{~mm}$ to $3.2 \mathrm{~mm}$. The samples were preconditioned at $50{ }^{\circ} \mathrm{C}$ in a vacuum oven for at least 7 days prior to testing. For the cone and radiant panel tests, the samples were conditioned at $50-55 \%$ relative humidity, $22{ }^{\circ} \mathrm{C}$ for one month. The $0.6 \mathrm{~m}$ diameter samples were obtained by gluing the boards together with wood glue before cutting the rounds.

\footnotetext{
"In order to describe materials and equipment it is occasionally necessary to identify commercial products by manufacturer's name. This does not imply endorsement by NIST nor does it imply that the particular product is the best available for that purpose.
} 


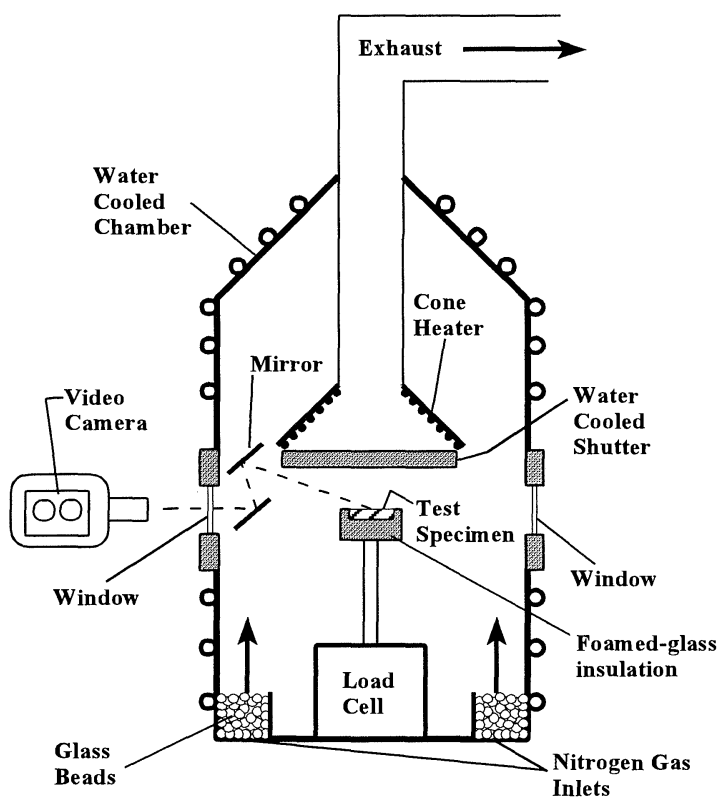

Figure 1. Schematic diagram of the gasification apparatus.

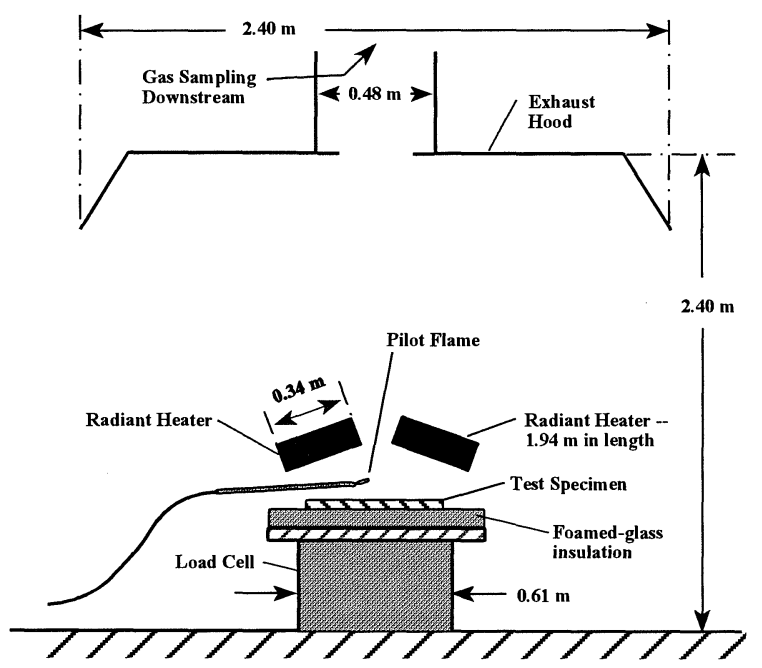

Figure 2. Schematic diagram of the large radiant panel facility. 


\section{RESULTS}

\section{Gasification Tests in Nitrogen}

Gasification tests of the $0.1 \mathrm{~m}$ diameter samples in nitrogen were run at three different heat fluxes: $20 \mathrm{~kW} / \mathrm{m}^{2}, 40 \mathrm{~kW} / \mathrm{m}^{2}$, and $60 \mathrm{~kW} / \mathrm{m}^{2}$. Repeatability of test results was within $12 \%$. The experimental mass loss fluxes are compared with predictions in Fig. 3. Looking at the experimental data, there was a large initial spike in the mass loss rate when the material was first exposed to the flux for the $40 \mathrm{~kW} / \mathrm{m}^{2}$ and $60 \mathrm{~kW} / \mathrm{m}^{2}$ cases. The magnitude of this spike increased with increasing flux level. This spike was followed by a settling period during which char-layer formation slowed the gasification rate. As the test ended, the rate rose slightly for the $20 \mathrm{~kW} / \mathrm{m}^{2}$ and $40 \mathrm{~kW} / \mathrm{m}^{2}$ cases as the backside boundary condition began to affect the material temperature. The numerical predictions tend to follow the overall data trends for the $40 \mathrm{~kW} / \mathrm{m}^{2}$ and $60 \mathrm{~kW} / \mathrm{m}^{2}$ flux, but overpredict the magnitudes of the initial spike and second peak, and underpredict the settling period. For the $20 \mathrm{~kW} / \mathrm{m}^{2}$ test, the model overpredicted the entire mass loss rate curve.

Note that in order to compensate somewhat for the cooling effect of the nitrogen purge on the backface boundary, the model employed a blackbody-radiation condition at this surface.

Considering the number of inputs required, the approximate nature of the material properties variations through the wood/char, and the neglect of moisture effects, the condensed-phase model worked reasonably well at predicting the gasification rate for the higher fluxes.

\section{Burning Tests/Diameter Effect}

The heat release rate curves from the burning tests are compared to the theoretical predictions for the $0.1 \mathrm{~m}$ diameter (Fig. 4) and $0.6 \mathrm{~m}$ diameter (Fig. 5) samples. In all tests, an external flux of $25 \mathrm{~kW} / \mathrm{m}^{2}$ was applied. The model, which employed an adiabatic boundary condition at the substrate's backside for both burning-rate simulations, predicts the heat release rate fairly well for the $0.1 \mathrm{~m}$ case. For the $0.6 \mathrm{~m}$ case, the model predicts a reasonably-shaped curve, but one that consistently falls below the experimental data. In both cases there is a sharp initial peak due to the initial gasification rate of unprotected material, followed by a settling period during which the char formation reduces the gasification rate. Finally, there is a slow increase as the insulating back boundary forces the material temperature to increase, thus enhancing the gasification process, followed by a decrease as the virgin wood material is consumed.

The model does not predict the ignition-delay time very well. The critical mass flux for piloted ignition, which is an input to the model, was taken from the literature [23] and may be a little low for this experimental configuration. Also, the presence of moisture, which is not taken into account by the model, would increase the ignition time. Another source of test-to-test variation and model-to-test differential for the large radiant panel burning tests $(0.6 \mathrm{~m}$ case) is cracking (typically along the glued edges) and warping (exposing the bottom surface) of the sample. This would increase the burning surface area, an effect which is not included in the model predictions of heat release rate, and likely is responsible for a good portion of the model's underestimate shown in Fig. 5. It should be noted that the prediction of the second peak was very sensitive to the substrate's thickness and backface boundary condition.

Looking at the effect of diameter, the heat release rate curves are essentially the same except for the magnitude of the sharp first rise and the initial portion of the settling period. Both the experimental and theoretical curves show that a larger sample yields a larger peak. Initially, in 


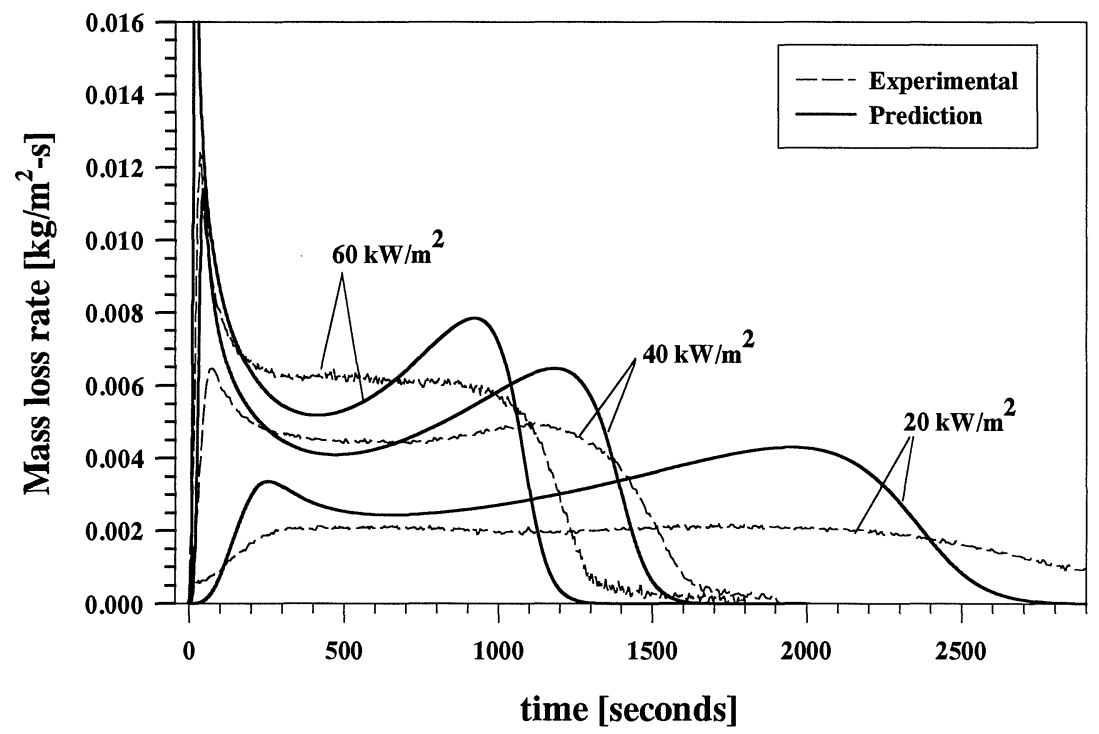

Figure 3. Comparison of gasification results with model predictions for Douglas Fir at external heating rates of 20,40 and $60 \mathrm{~kW} / \mathrm{m}^{2}$.

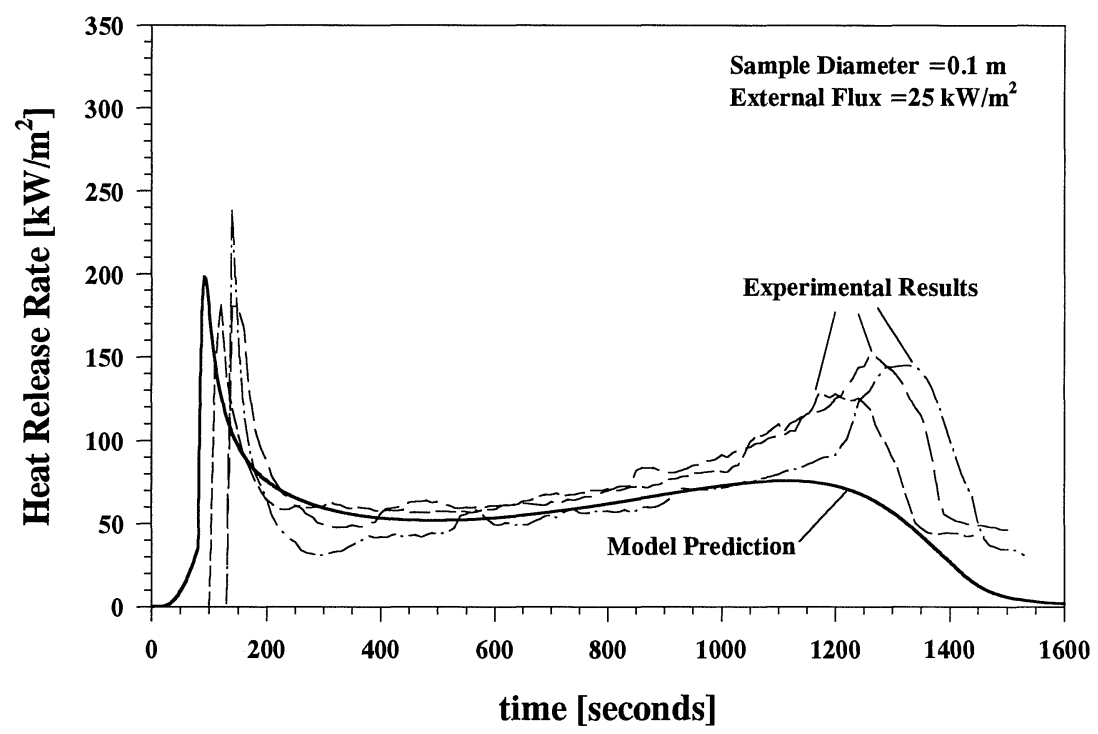

Figure 4. Comparison of experimental heat release rate measurement with model prediction for $0.1 \mathrm{~m}$ diameter Douglas Fir sample. 


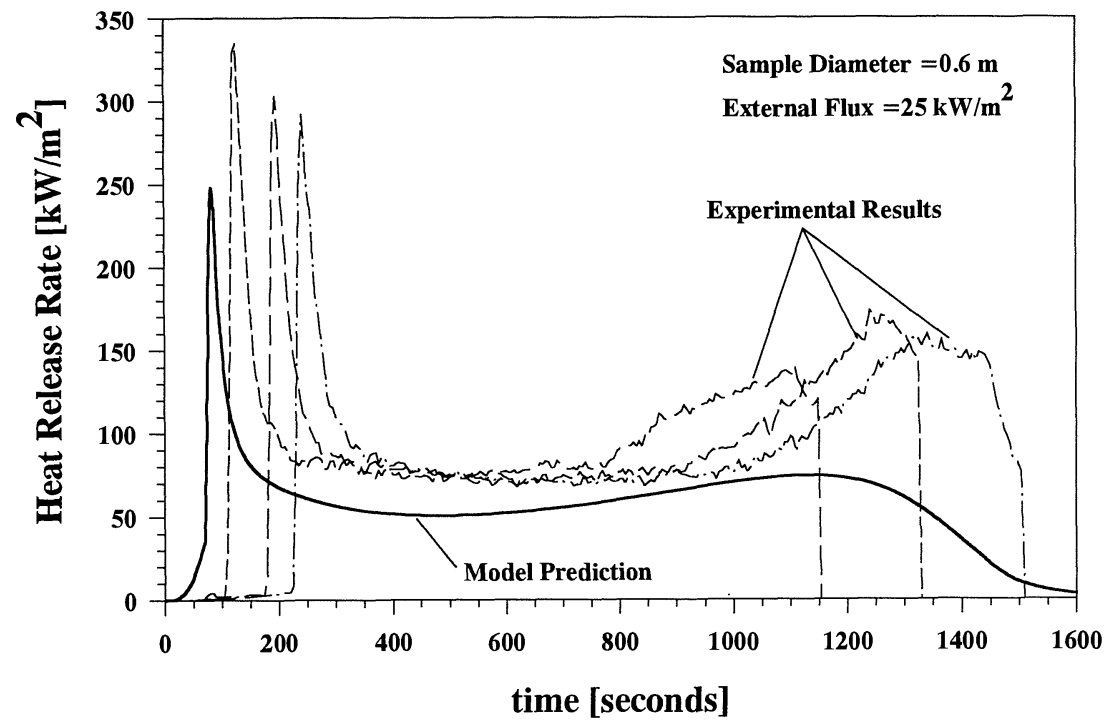

Figure 5. Comparison of experimental heat release rate measurement with model prediction for $0.6 \mathrm{~m}$ diameter Douglas Fir sample.

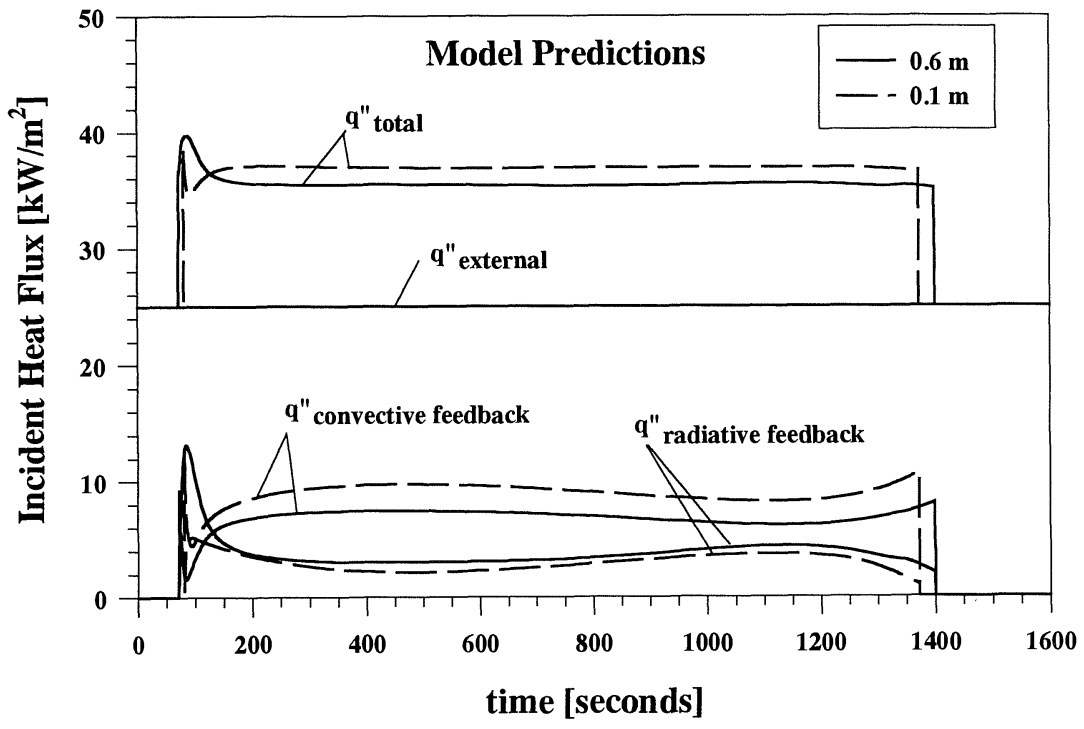

Figure 6. Model predictions of the incident heat flux breakdown for the $0.1 \mathrm{~m}$ and $0.6 \mathrm{~m}$ diameter Douglas Fir samples. 
the absence of char, the flame height was much greater for the $0.6 \mathrm{~m}$ sample, which resulted in a larger radiative heat feedback value. This can be seen in Fig. 6, which shows predictions for the convective and radiative heat feedback components of incident flux to the sample surface. As the char forms, the flame height rapidly drops and the difference between the two samples (with respect to heat release rate) becomes small. The drop in flame height was observed in the experiments: the flame height for the $0.6 \mathrm{~m}$ sample was $>0.66 \mathrm{~m}$ just following ignition and dropped to $\sim 30 \mathrm{~mm}$ within 90 seconds. At the lower height, the flame zone comprised many small flamelets covering the surface and did not resemble a single coherent flame. This burning phenomenon also was observed in the cone calorimeter tests of the $0.1 \mathrm{~m}$ diameter samples. The maximum flame height could not be measured because of the heater but the $20 \mathrm{~mm}$ to $30 \mathrm{~mm}$-tall flamelets on the surface were observed later in the test.

The predicted total flux to both samples during the quasi-steady portion of the test is about the same $\left(\sim 35.5 \mathrm{~kW} / \mathrm{m}^{2}\right.$ to $37 \mathrm{~kW} / \mathrm{m}^{2}$, including the $25 \mathrm{~kW} / \mathrm{m}^{2}$ external flux $)$ but the radiative and convective component breakdown is slightly different as shown in Fig. 6 . The $0.1 \mathrm{~m}$ diameter sample has a higher convective term than the larger sample. The $0.6 \mathrm{~m}$ diameter sample makes up some of this difference by having a larger radiative feedback term. The model predictions also show the change in the incident flux breakdown during the course of a test. As sample diameter increases for a non-charring quasi-steady pool fire, the radiative feedback term becomes the dominant source of heat feedback [1]. The predictions show this effect initially, when there is little char formed on the surface. However, for wood, the drop in flame height due to the insulating char layer results in a smaller radiative component relative to the convective component during the quasi-steady portion of the test. At the end of the test (when the gasification rate is increased by the influence of the back boundary condition), the radiative feedback term increases for both samples.

\section{CONCLUSIONS}

Both the experiments and model predictions show that, with the exception of the initial peak burning rate and its effect on the first portion of the settling period, sample diameter for intermediate scale fires (between $0.1 \mathrm{~m}$ and $0.6 \mathrm{~m}$ ) has little influence on the heat release rate under fire conditions for horizontal wood. The predictions of the second peak, however, were very sensitive to the insulating substrate's thickness and backface boundary condition, suggesting that experimental heat release rates may be highly dependent on the thickness of the underlying insulation. The explanation for the lack of diameter or size effect lies in the gasification-rate reduction caused by the insulating influence of the char layer. As the gasification rate drops, the difference in the flame height between the different diameter samples is reduced. Theoretical analysis indicates that despite differences in the makeup (i.e. convective versus radiative) the total heat feedback to the surface is approximately the same for char-forming samples of diameters 0.1 $\mathrm{m}$ and $0.6 \mathrm{~m}$. Because the flame height drops, the radiative component does not become the dominant source of heat feedback for charring materials as the diameter increases. The importance of the initial spike in the heat release rate curve depends on the specific fire scenario. The impact, as these results show, would not be to the remaining wood, but on enhancing the fire spread to the surrounding materials.

\section{ACKNOWLEDGEMENTS}

The authors thank Dr. Marc Janssens and Dr. William Parker for sharing their invaluable technical insight on the burning of wood and Dr. Robert White for providing the test samples. 


\section{REFERENCES}

[1] Burgess, D. and Hertzberg, M. "Radiation from Pool Flames," in Afgan, N.H. and Beers, J.M., ed. Heat Transfer in Flames, John Wiley \& Sons, New York, NY, Chap. 27, 1974.

[2] Shaw, J.R. and Urbas, J. "An Intermediate-scale Calorimeter for Building Materials and Assemblies," Fire and Materials, 17:6, 259-264, 1993.

[3] Hamins, A., Fischer, S.J., Kashiwagi, T., Klassen, M.E., and Gore, J.P. "Heat Feedback to the Fuel Surface in Pool Fires," Combust. Sci. and Tech., 97, 37-62, 1994.

[4] Parker, W.J. "Prediction of the Heat Release Rate of Douglas Fir," Proceedings of the 2nd Int. Symp. on Fire Safety Science, 337-346, 1989.

[5] Atreya, A. "Pyrolysis, Ignition and Fire Spread on Horizontal Surface of Wood," Natl. Bureau of Stds. Report NBS-GCR-83-449, 1984.

[6] Steckler, K.D., Hamins, A., and Kashiwagi, T. "A Model for the Burning of a Horizontal Slab of Wood: Status Report," NISTIR 5499 - NIST Annual Conf. on Fire Research: Book of Abstracts, 111-112, 1994.

[7] Fredlund, B."A Model for Heat and Mass Transfer in Timber Structures During Fire, A theoretical, numerical and experimental study, Report LUTVDG(TVBB-1003), Sweden, Department of Fire Safety Engineering, Lund University, Sweden, 1988.

[8] Brown, D. "027. What are the Right Numbers for the Modelling of Wood Fires?", W-I-P Poster Session: Chem: Mechanisms and Modeling, 274.

[9] Siegel, R. and Howell, J.R., Thermal Radiation Heat Transfer, 2nd ed., p. 669, Hemisphere Publishing Co., New York, 1981.

[10] Leckner, B. "Spectral and Total Emissivity of Water Vapor and Carbon Dioxide," Comb. and Flame, 19, 33-48, 1972.

[11] Yuen, W.W and Tien, C.L. "A Simple Calculation Scheme for the Luminous Flame Emissivity," 16th Symp. (Int.) on Combustion, The Comb. Inst., Pitts., PA, 1481-1487, 1982.

[12] Orloff, L. and de Ris, J. "Froude Modeling of Pool Fires," 19th Symp. (Int.) on Comb., The Comb. Inst., Pittsburgh, PA, 885-895, 1982.

[13] Heskestad, G. "Luminous Heights of Turbulent Diffusion Flames, " Fire Safety Journal, $\underline{5}$, 103-108, 1983.

[14] Tien, C.L. and Lee, S.C."Flame Radiation,"Prog. in Energy \& Comb. Sci., $\underline{8}, 41-59,1982$.

[15] Bard, S. and Pagni, P.J. "Carbon Particles in Small Pool Fires," Journal of Heat Transfer, $\underline{103}, 357-362,1981$.

[16] Tewarson, A. "Smoke Point Height and Fire Properties of Materials," NIST-GCR-88-555, Natl. Inst. of Stand. and Tech. Report avbl. through Natl. Tech. Inf. Serv., Springfield, VA 22161 USA.

[17] Yang, J. Hamins, A. and Kashiwagi, T. "Estimate of the Effect of Scale on Radiative Heat Loss Fraction and Combustion Efficiency," Comb. Sci. and Tech., 96, 183-188, 1994.

[18] Reid, R.C., Prausnitz, J.M. and Sherwood, T.K. The Properties of Gases and Liquids, 3rd ed., McGraw-Hill, New York, 1977.

[19] Delichatsios, M.A. "Air Entrainment into Buoyant Jet Flames and Pool Fires," Comb. and Flame, 70, 33-46, 1987.

[20] Lockwood, R.W. and Corlett, R.C. "Radiative and Convective Feedback Heat Flux in Small Turbulent Pool Fires with Variable Pressure and Ambient Oxygen," Proc. of the ASME-JSME Thermal Eng. Joint Conf., V. 1, 421-426, 1987.

[21] Hamins, A., Yang, J.C., and Kashiwagi, T. "A Simple Model for Predicting the Burning Rate of Condensed-Phase Pool Fires," NISTIR in preparation.

[22] Babrauskas, V. and Peacock, R. "Heat Release Rate: The Single Most Important Variable in Fire Hazard," Fire Safety Journal, 18, 255-272, 1992.

[23] Simms, D.L. "Damage to Cellulosic Solids by Thermal Radiation," Comb. and Flame, $\underline{6}$, 303-318, 1962. 